\title{
EL DÉFICIT LINGÜÍSTICO EN EL JOVEN POSMODERNO
}

Sara Elvira Galbán Lozano

Fabiola E. Saúl Gavito

\section{RESUMEN}

LA ÉPOCA POSMODERNA, CON SUS CARACTERÍSTICAS PARTICULARES, HA traído retos que han de resolverse desde las distintas ciencias. La Pedagogía no es la excepción, pues aunque el hombre en esencia sigue siendo el mismo, actualmente está inmerso en una serie de situaciones específicas: es el caso del déficitlingüístico, en donde predomina el uso precario de la lengua, existe una falta de contenido en aquello que se comunica y una limitación en el bagaje léxico. Esto ocasiona la pérdida o al menos la merma de la facultad lingüística, y por ende, la riqueza del alma, pues es mediante el lenguaje que el hombre se comunica con el exteriory, expresándose a sí mismo, expresa su serde persona.

\section{ABSTRACT}

The post-modern period, with its particular characteristics, has camied challenges to be solved from the differentsciences. Pedagogy is not the exception: although man keeps being in essence the same, today he is immersed in a senies of specific situations. It is the case of the linguistic deficit, in which the poor use of the language prevails, there is a lack of content in what is communicated and a limitation of the lexical baggage. It provokes the losing or atleasta reduction of the linguistic ability and, therefore, the richness of the soul, because it is through languages that man can communicate with the external world and, by expressing himself, expresses his individual being. 


\section{INTRODUCCIÓN}

La humanidad como tantas veces, está viviendo un peńodo de transición. El hombre actual está reclamado poruna serie de estímulos que no le permiten ni siquiera detenerse a reflexionar sobre su propia vida. Aparentemente, muchos caminan sin rumbo, sólo alimentando sus necesidades materiales más inmediatas, sin preocuparse por cultivarsu espíitu o por conocery dara conocer la gran riqueza que éste encierra.

Esto que se ha convertido en una forma de vida es producto de las crisis sucesivas que ha sufrido la humanidad, marcadas por comientes de pensamiento con claras manifestaciones en la vida diania. Éste es el caso de la modemidad que concibió en la Ilustración un proyecto que no ha sido capaz de culminar. las ideas de libertad y de razón ${ }^{1}$. O el caso de la posmodemidad, que según Lipovetsky, se ve marcada porla lógica del vacío; el hombre se ve inmerso en el huracán de la vida sin saber a dónde dinigirse, pues dentro de sí sólo encuentra desolación.

No podemos, con tan pocos elementos, definirel espíitu de nuestra época. Es necesanio determinarcuáles son las causas de su propagación y de su afincamiento en nuestra sociedad. Por tanto, el presente escrito estudiará lo que fue la modemidad para tratarde explicarel fenómeno dela posmodernidad, que es la forma en la que se ha denominado la época presente, y darpaso a nuestro objeto central de estudio: el uso precario de la lengua en el joven posmoderno mismo que hemos denominado déficitlingüístico.

Cabe señalarque el discurso que se presenta en tomo a la cuestión del uso precario de la lengua, es sobre todo un discurso conscientizador que busca, a partir de la definición de los conceptos que con él se relacionan, legar a captar la trascendencia del problemay, así, determinar líneas de acción pedagógicas que colaboren no sólo a subsanar el problema, sino a prevenirlo. Es por esto que la propuesta pedagógica específica (contenida al final del presente artículo) es tan sólo una de las muchas posibles y se presenta a manera de ejemplo. 


\section{MODERNIDAD}

Debido a su situación histónca, la modemidad se entiende como un proceso de mundanización o secularización. La repentina aparición de los humanismos renacentistas, la recuperación del materialismo griego y las posibilidades de dominio sobre el mundo que abrió la ciencia positiva, hablan a favor de esta interpretación como una toma de conciencia de su singularidad en contraste con los dualismos de la filosofía medieval.

La mayoría de los teóricos sitúan su comienzo en torno a la Ilustración, la era de la razón; aunque también puede hablarse de una etapa más avanzada de la modemidad llamada modemidad postenoro alta, cuyo comienzo se establece hacia mediados o finales del siglo XIX.

A pesarde que la nomenclatura y el peńodo que abarca la modernidad es aún cuestión de discusión, es un hecho que sus caracteństicas principales se reconocen y aceptan de manera general. Y es así cómo, en sus raíces, la modemidad es una condición social impulsada y sostenida por la fe de la Ilustración en el progreso científico racional, en el triunfo de la tecnología sobre la naturaleza, y en la capacidad de controlary mejorar la condición humana mediante la aplicación de conocimientos científicos y tecnológicos. Se buscó construir sistemas que explicaran todo, que justificaran racionalmente la existencia de cualquier cosa, sin omitirnada; sistemas que dieran cuenta de la razón suficiente de totalidad. Chesterton sustenta que la modemidad es pasar de un mundo en el que podía creerse casi todo, a otro en el que ya no puede creerse casi nada, porque cualquier misteno debeńa sustituirse por una hipótesis científica². Es la época de Descartes, de Hegely de Kant, adoradores por excelencia de la razón, en la que buscaban todas las explicaciones, sin concebir que el hombre es un serintegrado, compuesto no sólo de razón.

La modemidad se convirtió en un fenómeno con dos caras: una, portadora del enaltecimiento de la condición humana, la racionalidad (que ciertamente, es la cualidad superior del hombre, misma 
que, junto con la voluntad, le colocan en la cúspide de los seres materiales existentes), otra, la de su empobrecimiento. Esto puede apreciarse en diversos campos:

- Desde el punto de vista económico, la modernidad empieza al separarse la familia y el trabajo - a causa de la concentración racional de la producción en el sistema fabril- y culmina con los sistemas de producción en masa.

- Desde el punto de vista político, contempla la consolidación del Estado nacional, como fuerza militar, y la creación del estado de bienestar, que se presume civilizadory dignificador. Ello ocasiona la aparición de Estados totalitarios.

- Desde el punto de vista de la organización, las escuelas han hecho grandes esfuerzos por satisfacer las exigencias de educación, otorgando oportunidad de estudio a una gran cantidad de jóvenes. Sin embargo, esto, en muchas ocasiones, ha llevado a la impersonalización de la enseñanza y a la falta de sensibilidad ante las necesidades particulares ${ }^{3}$.

Aunque las diferentes comientes de pensamiento no han sido sustituidas de manera absoluta, pues encontramos rasgos modemos mezclados con rasgos posmodemos, podemos hablar de una nueva forma de pensamiento que se permea en todos los ámbitos: la posmodernidad.

\section{LA CONDICIÓN POSMODERNA}

Como todas las comientes de pensamiento, la posmodemidad es evasiva y múltiple, y se resiste a serplenamente caracterizada y clasificada. Aparentemente, no se sabe bien qué es, sin embargo, se caracteriza por la oposición a los principales dogmas de la modemidad, el racionalismo y la Ilustración, pues se considera que la razón falló, al producir guerras y genocidios, hambre e injusticia ${ }^{4}$.

La mayorparte de los autores sitúan los ońgenes de la condición posmoderna alrededor de los años sesenta del siglo XX. La posmodernidad constituye una situación social en donde la vida eco- 
nómica, política, de organización e incluso personal, se organiza en torno a principios diferentes a los de la modernidad. El posmodernismo no pretende destruir el pasado, sino asimilarlo y conducino por caminos dispersos y aun contranios. No busca una solución a los problemas por la vertiente de la Economía o del Derecho, sino porel fortalecimiento de sus vínculos o ligaduras personales y comunitarias.

Así las cosas, es momento de establecer un marco teónico de la posmodemidad. Éste estarárepresentado poralgunas posturas en cuanto a la concepción del término mismo y de sus diferentes acepciones.

Porsu utilidad, se atenderá a la división que hace Habermas. Este autor divide las comientes posmodemas de la siguiente manera:

a) Filosofía de la praxis. Defiende la modernidad y el universalismo ético, en donde el fin justifica los medios.

b) Los neoconservadores disfrutan los logros de la modemidad al margen de la moral (materia sobre espínitu).

c) Los antimodemos o propiamente posmodemos rechazan la racionalidad de la modemidad reclamando las pulsiones espontáneas de la imaginación y de la afectividad. Denuncian la razón instrumental y, en su lugar, queda desenmascarada la voluntad de poder, el hedonismo y el cinismo.

d) Los paleoconservadores rechazan la modernidad y proponen una vuelta a posiciones antiguas como el neoanistotelismo. Podńamos llamarlos humanistas, porque proponen la virtud como solución ${ }^{6}$.

Después de considerar estas posturas es posible afirmar que lo señalado por Carlos Llano, en «a posmodernidad en la empresa», es una realidad. Considera que la posmodernidad es un cajón de sastre donde se incluyen todos aquellos fenómenos sociales que van contra las ideas universalmente aceptadas hasta hace apenas dos décadas. De la misma forma, Rafael Gómez Pérez en su libro «Ni de letras ni de ciencias»retoma esta idea para definir la universidad de finales del siglo XX y principios del XXI. 
Para Alejandro Llano, la posmodemidad es una comiente imprecisa, caracterizada por tres notas fundamentales: es polimorfa, porque representa múltiples caras y matices; es acumulativa, pues no pretende destruirel pasado, como intentaron otras tendencias revolucionanias, sino asimilanlo; y es ambigua, porque ante ella se abren caminos dispersos y aun contrarios, que pueden ser muy beneficiosos o perjudiciales para el hombre.

Algunas caracteństicas de la posmodemidad son:

- Filosófica e ideológicamente, los avances en las telecomunicaciones junto con la divulgación más ampliay más rápida de la infomación, están cuestionando las antiguas certezas ideológicas a medida que las personas constatan que existen otras formas de vivir. Incluso la certeza cientíica está perdiendo credibilidad, cuando presuntos descubrimientos definitivos de la modemidad (sobre cosas como el café descafeinado y el calentamiento global) son cuestionados, e incluso superados, por otros nuevos descubrimientos a una velocidad cada vez mayor.

- En la política hay una vuelta, al menos aparente, a posiciones moderadas y a una economía conservadora. La guerra fría, aunque con sus altibajos, ha terminado. Ahora la lucha ya no se centra en las posiciones socialistasy capitalistas - porque en cierto sentido, el socialismo ha desaparecido- , sino que se imprime en el poder económico de la expansión de los mercados comunes.

- Desde el punto de vista económico, las sociedades posmodemas asisten al declive del sistema fabril. Las economías posmodernas se estructuran en torno a la producción de más bienes pequeños que grandes, a los servicios más que a las manufacturas, a la información y a las imágenes más que a los productos?.

- La ciencia ha tenido un despliegue monumental. Hemos presenciado el boom de las tecnologías. La cibernética y la robótica abren un honizonte incalculable a las capacidades humanas.

- La crisis casi generalizada de valores es otra característica al igual que las crisis causadas por las luchas étnicas, que han desplazado a millones de personas, convirtiéndolas en refugiados. 
- El mundo de hoy tiene poco aprecio por el ejercicio de la razón. Hay un descenso en el cultivo de la inteligencia, por lo que los estudiantes crecen en intereses prácticos, inmediatos y vitales, y decrecen en intereses teónicos debido al poco ejercicio del razonamiento abstracto. Esto, entre otras cosas, se debe a que la hegemonía está en manos de la imagen, que es sensible y portanto no es un saberen el sentido cognoscitivo. La propagación exacerbada de la televisión ha provocado, en muchos casos, la atrofia de la capacidad de reflexión $\mathrm{y}$, con ella, la capacidad de entender, y portanto, de distinguirentre lo verdadero y lo falso. No aventuradamente habla Sartori del homo videns, que sustituye al homo sapiens ${ }^{8}$. Es así como el pensamiento se ve afectado, al disminuir el medio de expresión del mismo: el lenguaje. Esto nos introduce directamente al asunto del déficitlingüístico, que aunque se puede manifestaren cualquier ámbito, es aún más preocupante detectarlo en losjóvenes universitarios.

Para explicar la naturaleza de este fenómeno y sus consecuencias, será necesario explicarpreviamente algunos conceptos relacionados.

\section{PENSAMIENTO, LENGUAJE Y LENGUA}

El hombre es un ser corpóreo espiritual, y precisamente es esto lo que hace posible el conocimiento. El conocimiento sensible es aquel que parte de los sentidos externos (propios del cuerpo) y los internos (sentido común, imaginación, memoria y cogitativa). De este tipo de conocimiento se pasa al intelectual, en el cual el hombre avanza hasta el núcleo esencial de las cosas, plantea cuestiones relativas a la esencia, existencia y sentido de las mismas, y expone las respuestas de ellas en forma intelectual. Lo que caracteriza a este tipo de conocimiento es la abstracción de la esencia de lo conocido porlos sentidos. El producto de esta operación es el concepto, y éste, enunciado, es la palabra.

Cuando el hombre con su inteligencia afirma o niega algo acerca de la cosa conocida, se dice que concibe un juicio, cuyo producto es la proposición, y al realizarun juego de proposiciones y obtener con- 
clusiones no evidentes, se dice que hace un raciocinio, emitiendo un raciocinio. Estas tres etapas son las que componen el conocimiento intelectual (propio del espínitu) y, de manera general se puede decir que constituyen el pensamien to del hombre, aunque ciertamente existen otros procesos a partir de estas tres instancias fundamentales.

En cuanto a la relación pensamiento-lenguaje los estudiosos sostienen que éste es el vehículo del pensamien to ${ }^{9}$, es decir, que es el elemento que de alguna manera pemite el discurrir del pensamiento. Cabe hacer notar la primacía del pensamiento sobre el lenguaje, no sólo en cuanto a su génesis, sino a que no origina una relación de dependencia con el lenguaje, mientras que éste, sin el primero, no puede existir. Es decir, el lenguaje contiene el pensamiento, o el pensamiento es la forma ${ }^{10}$ del lenguaje.

Es por eso que el lenguaje proviene en cierto sentido de la inteligencia, aunque como el hombre es un ser sumamente complejo, es evidente que el lenguaje también se relaciona con la voluntad y con su esfera afectiva. Así, se puede definirel lenguaje como la manifestación específicamentehumana delasafeccionesdelalma, peroespecialmentedela operación del intelecto, quefacilita al hombrela exteriorización delo queleaconteceen el ámbito del espíritu, por lo quees, asimismo, inmaterial. Como afecciones del alma se entienden, parafraseando al Estaginita ${ }^{11}$, los pensamientos de la inteligencia, las decisiones de la voluntad y los movimientos de la afectividad. Su importancia es tal, que no sólo se puede afirmar con Pedro Salinas que el lenguaje es el instrumento pormedio del cual el hombre toma posesión de la realidad y se adueña del mundo ${ }^{12}$, sino que es el único medio existente para que el hombre comunique la enome riqueza que tiene en su interior, en su alma.

Es así como la naturaleza espinitual del lenguaje tiene su fundamento en la realidad, pues a través de los procesos de conocimiento intelectual surge la facultad lingüística como medio para nombrar lo que se conoce y para darlo a conocer a los demás. Así, puede afirmarse que el lenguaje tiene una connotación directa con la reali- 
dad, de la misma manera que la tiene el conocimiento intelectual humano. Por tanto, la tríada: realidad, pensamiento y lenguaje, es una entidad compacta en la que sus elementos se encuentran intrínsecamente unidos.

De todo lo anterior se deducen las diversas funciones que tiene el lenguaje en el hombre. La pimera, que podńa llamarse denominativa, es precisamente aquélla a la cual se ha estado aludiendo a lo largo de este texto, es decir, a los nombres que las cosas reciben después de serconocidas por el hombre.

La función comunicativa es aquélla en la cual el lenguaje es el medio de comunicación que el hombre utiliza para exterionzar lo que acontece dentro de sí, y se relaciona con la función expresiva, la cual, sirviendo para lo mismo, hace referencia exclusivamente al ámbito afectivo y sensitivo del hombre ${ }^{13}$.

Por último, cabe decir que la posibilidad del hombre para proyectarse a futuro, de abstraer el aquí-ahora ${ }^{14}$, entendenlo y comunicarlo, sólo puede ser expresado a través del lenguaje, ésta sería la función denominada especulativa.

La dimensión espinitual del lenguaje es evidente cuando se entiende que es manifestación del alma humana, pero también es fácilmente comprobable por el hecho de que las computadoras, por más que utilicen el lenguaje, nunca podrán reflexionar sobre él, ni entender los matices tan diversos que una frase puede tener en diversas circunstancias ${ }^{15}$.

Cabría preguntarse, ccómo es posible que el lenguaje sea inmatenial o espiritual, si se puede very oír?O mejor aún: si es algo que proviene del intelecto humano, y es algo que posee todo hombre, porqué algunos dicen pájaro, otros, bird y otros oiseau?Es así como se descubre un tercer elemento: la lengua.

Como se puede deducir, la lengua es la concreción cultural del lenguaje en una sociedad y cultura específicas, y porende, tiene una estructura establecida. Porlo tanto, el factorconvencional de la lengua hace que sea necesanio aprenderla, pues posee una senie de reglas. 
Uno de sus elementos esenciales es el signo, elemento sensible y material que transmite un concepto, una idea o un mensaje de naturaleza inmaterial. Las lenguas se construyen a partir de un sistema de signos ordenados.

Como puede observarse, la relación pensamiento-lenguaje-lengua es tan estrecha que resulta difícil distinguir, en ocasiones, los tres elementos en los procesos de comunicación cotidiana. Para entenderdicha relación podńa decirse que el pensamiento es una carreta, el lenguaje es el camino porel cual corre (discurre) el pensamiento, y la lengua es el material concreto del cual está hecho el camino. De la misma manera como puede habercaminos de tierra, pasto, concreto, piedras, igualmente se puede hablarde lengua castellana, inglesa, francesa.

Una vez aclarados estos conceptos, será posible entender la gravedad del problema del déficitlingüístico y sus manifestaciones.

\section{EL DÉFICIT LINGÜÍSTICO}

Es un hecho innegable que la riqueza de la lengua se ha reducido en especial en losjóvenes, pues aunque hablan mucho, no hacen uso del acerbo léxico de su lengua, y se quedan con unas cuantas palabras trilladas y casi vacías de significado.

Tal parece que el arte de conversar es cosa de generaciones pasadas. Esta capacidad de sosteneruna conversación o un diálogo enniquecedor, que en otras épocas era conocida como retónica, hoy se ha perdido. Como señala Salinas, el nightclub se erige sobre los salones y tertulias, donde la actividad principal era la conversación, y sólo se buscan actividades «que oscilan entre el apechugamiento y la contorsión [...], que no requieren un léxico más allá de la docena de palabras, ni una actividad pensante superiora la del párvulo $\Downarrow^{6}$.

Debido a que la palabray el lenguaje tienen una función mediadora entre la realidad y el hombre, y entre un hombre y otro hom$\mathrm{bre}^{17}$, la principal consecuencia de ello es la supresión de la relación con la realidad, misma que conlleva a la anulación, tanto de la comu- 
nicación como de la capacidad de aprenderpor medio del lenguaje.

Además, la falta de atención afecta tanto al lenguaje como a la comunicación pues genera actos comunicativos falsos, en los que uno emite palabras, otro las percibe y realmente no se comunica nada. Esto trae como consecuencia lo que Alfonso López Quintás denomina el «ecuestro del lenguaje»: las personas practican modos de pensary de hablar superficiales, toscos, banales, imprecisos y cargan al lenguaje con una dosis subjetiva de emotividad, ocasionando que no se hable bien y reduciendo a una cantidad mínima de palabras con las que cuenta una lengua, y adoptando formas redundantes de hablarque en sí mismas no expresan mucho ${ }^{19}$.

Entre las causas del déficitlingüístico del hombre posmodemo, se pueden citardos. La primera, es lo que Salinas denomina la psicosis de la prisa ${ }^{20}$ : el vertiginoso movimiento del hombre actual impide, de alguna manera, el pensar pausado que propicia el diálogo profundo y rico. La otra causa es la cultura de la imagen: el bombardeo excesivo de imágenes atenta contra la lingüisticidad del hombre, impide su capacidad discursiva. Asimismo, reduce la posibilidad de obtenerconclusiones a partirde razonamientos, pues todo se le presenta de manera inmediata y digerida, evitando el esfuerzo de razonar, inferiry deducir.

Ciertamente, no podemos satanizar a la imagen pues mientras más posea una persona, contará con mayores elementos para ennquecer su pensamiento. El problema con la cultura de la imagen es que bombardea de tal manera al hombre posmoderno, que no le permite reflexionar sobre aquello que conoce, quedándose en un conocimiento meramente superficial.

Este bloqueo del lenguaje no sucede de un momento a otro: es fruto de una habituación. Por ende, la vida del hombre posmodemo, que acontece entre mensajes meramente visuales la mayor parte de su día, no sólo ha permitido que su lingüisticidad se adormezca, sino que también deja de actualizar su potencia de comunicarse; recibe mensajes, sí, pero no los emite, y cuando lo hace, ya no en- 
cuentra respaldo en su lenguaje ni en su capacidad de discumir. Así, acude a la repetición, al mensaje superficial, a palabras comodines que utiliza para nombrar objetos de la más diversa índole ${ }^{21}$, a los clichés, y evidentemente, a los slogans televisivos.

Es como si los hombres se hubieran convertido en gentecita con cabeza de cinescopio, pues parece como si las ondas que emite el televisor expidieran sustancias extrañasy adormecieran las neuronas, convirtiéndole cada vez más en un hombre de monosílabos.

Las consecuencias de la pérdida de conversación o el diálogo en la vida cotidiana no son pocas, y mucho menos, leves. En primerlugar puede decirse que el hombre se comunica cada vez menos consigo mismo, es decir, que no se da a conocer en el diálogo, y porende, se conoce cada vez menos. Por ello, señala Pedro Salinas que «el hombre se posee en la medida en que posee su lengua»y que no habrá ser humano completo, es decir, que se conozca y se dé a conocer, sin un grado avanzado de posesión de su lengua. Porque el individuo se posee a símismo, se conoce, expresando lo que lleva dentro, y esa expresión sólo se cumple por medio del lenguaje $\not^{2}$. La niqueza del alma de la que se hablaba anteriormente corre peligro de perderse, pues al no sercomunicada permanece dentro del individuo, estéril. Y si éste ha bloqueado su capacidad de reflexión, tampoco llega a conocer sus pensamientos, sus decisiones, sus quereres, sus sentimientos, y entonces, no se conoce a sí mismo, no tiene nada que comunicar, no puede darse puesto que no se posee.

El problema de la pobreza de lenguaje, que en realidad es pobreza en el uso de la lengua, lleva a la casi-incapacidad de expresión; al no poderdecira los demás lo que se está pensando o sintiendo. Lleva, en fin, a una auténtica incomunicación del alma, que no puede actualizar la potencia de sociabilidad que le es propia por naturaleza.

Pero probablemente la consecuencia más seria, es que un manejo precario de la lengua puede llegar a obstruir el discurso del pensamiento, por falta de elementos lingüísticos. Hagamos referencia a la figura gráfica de la carreta: si el material del cual está hecho el cami- 
no se encuentra en mal estado (que es lo que pasańa con el uso precario de la lengua), la cameta no podrá comer a través de él. Y de hecho, esto es lo que sucede con el fenómeno del déficitlingüístico.

Así, puede observarse que estas consecuencias atentan contra ambas dimensiones del lenguaje: contra la comunicativa, apagándola y dejando al hombre sin elementos para ejercersu facultad social; contra la discursiva o racional, al impedir el comer o discumir del pensamiento y, en consecuencia, obstruyendo la posibilidad de actualizar su facultad racional y, por ende, de aumentarel conocimiento.

\section{EDUCACIÓN Y LENGUAJE}

La relación entre educación y lenguaje aparece evidente y a la vez compleja. Por tanto, la principal aportación del presente escrito es la sistematización de dicha relación en tres vertientes distintas, que hacen referencia a los distintos aspectos del hecho lingüístico. Cabe señalar que para encontrar un orden en la relación entre educación y lenguaje, se ha tomado también la lengua como un elemento importante en dicha relación.

En primerlugar, puede entenderse el lenguaje como instrumento dela educación, pues permite el fenómeno comunicativo entre el educadory el educando, mismo que facilita el surgimiento de la amistad entre ambos, medio ideal para el proceso de autoperfeccionamiento.

Las implicaciones pedagógicas del déficitlingüístico en esta vertiente señalan una comunicación débil, casi sin contenido, o bien, la comunicación de una realidad pobre, que desdibuja de alguna manera el fin de la educación. Se puede hablar de un discurso truncado y de un relato cojo.

También se puede decir que la lengua es un instrumento del conocimiento, pues - como ya se ha explicado - la palabra hace cognoscible la realidad. Es así como se logra el cultivo de la inteligencia y la formación de la voluntad y de la afectividad, pormedio de la exposición oral y escrita. Esta vertiente de la relación hace notar que el 
hombre no sólo conoce cosas concretas y materiales, sino que también se relaciona con las ideas de otros mediante aquello que lee 0 escucha.

Evidentemente, las implicaciones educativas más senias se desprenden de esta vertiente, pues el alumno que padece el déficitlingüístico encuentra que la lengua, en lugar de ser una aliada en el proceso de estudio, es un enemigo, una traba. Esto impide directamente el cultivo de su inteligencia.

Por último, puede hablarse de la lengua como contenido dela educación sistemática. Esto es un hecho evidente, pues la materia de español encuentra un lugar en el curículo de los diversos niveles del sistema educativo nacional. Así como existen asignaturas enfocadas a formar aspectos esenciales en el hombre, como su sociabilidad o su capacidad numénica, las materias relacionadas con el lenguaje educan su lingüisticidad, pues aunque es una facultad que se posee por naturaleza, la lengua ha de seraprendida debido a su estructura convencional. Así, existe la asignatura de Español, Lengua española, Redacción... En este sentido, puede hablarse de educación lingüística, así como se habla de educación cívica o moral.

Es precisamente esta última dimensión de la relación educaciónlenguaje de donde se desprende la propuesta pedagógica concreta.

La problemática surge ante el hecho de que el déficit lingüístico existe en los jóvenes universitarios, a pesar de que han cursado todas las materias de Lengua española que contempla el Sistema Educativo Nacional, tanto en el nivel básico como en el medio superior.

Por ende, es necesanio encontraruna manera de subsanar el déficitpor medio de una metodología no tradicional. En esta búsqueda se llegó a la propuesta del curńculo integrado de Villarini: en lugar de que cada uno de los elementos del mismo (sobre todo cada asignatura, con sus respectivos objetivos) se dinjan hacia metas diversas entre sí, se busque la manera de cohesionarel cuḿculo, buscando la formación integral del educando ${ }^{23}$. En este caso, se busca específicamente la educación lingüística del joven universitario. 
Así, en cada plan de estudios puede desamollarse el dominio de la lengua a través de todas las materias que lo componen. Para ello seńa necesanio, en primer lugar, hacer conscientes de esta necesidad a los profesores, y posteriomente invitarles a que añadan como objetivo anejo al objetivo general de su materia, el desarrollo de la lengua, diseñando distintas actividades de aprendizaje en torno a ello (lecturas de comprensión, análisis semántico y sintáctico, elaboración de ensayos), pero con sus propios contenidos.

Como fruto de esta investigación, se elaboró un compendio lingüístico que contiene una explicación de los elementos esenciales de la lengua española: gramática, redacción y ortografía; así como breves explicaciones teónicas de la naturaleza del lenguaje, de la lengua y de la relación de ambas con el pensamiento. Esto puede servir de apoyo para el profesoruniversitario.

La ventaja principal de esta propuesta es que puede aplicarse a cualquier licenciatura, sin importar el área de estudio y, así, lograrla educación lingüística en aquella etapa en la que es más necesaria para recomer el camino de los estudios universitarios y para enfrentar, posteniomente, las exigencias del mercado laboral caracteństico del mundo posmodemo.

Así, el pedagogo encuentra un nuevo perfil a su quehacer educativo: como educador lingüístico o como promotor del lenguaje en todos sus sentidos.

\section{REFERENCIAS BIBLIOGRÁFICAS}

${ }^{1}$ Cfr. YEPES, R, Entender el mundo dehoy., p.45.

${ }^{2}$ Cfr. BEUCHOT, M., Posmodernidad, hermeneútica y analogía., p.130133; INNERARTTY, M., Dialéctica dela modernidad., p.14, 17-18; LANO, C., El postmodernismo en la empresa., p.2-3.

${ }^{3}$ Cfr. HARGREAVES, A., Profesorado, cultura y posmodernidad., p.53-55. ${ }^{4}$ Cfr. BEUCHOT, M., Op.cit., p.7 y 13; YEPES, R., Op.cit., p.157 y 170. ${ }^{5}$ Cfr. BEUCHOT, M., Op.cit., p.120; HARGREAVES, A., Op.cit., p.36; LANO, C., Op.cit., p.XII. 
${ }^{6}$ Cfr. BEUCHOT, M., Op.cit., p.10-11.

${ }^{7}$ Cfr. HARGREAVES, A., Op.cit., p.36-37.

${ }^{8}$ Cfr. SARTORI, G., Homo videns., p.47, 52 y 102; YEPES, R., Op.cit., p.21-25.

${ }^{9} \mathrm{Cfr}$. CHOZA, J., etal., Filosofía del hombre: una antropología dela intimidad., p.268 ss; NUBIOLA, J., etal., Filosofía del lenguaje., p.97 ss.

${ }^{10}$ YEPES, R., FundamentosdeAntropología., p.51.

${ }^{11}$ Cfr. ARISTÓTELES., Organon: Perihermeneias., I, § 2.

${ }^{12}$ Cfr. SALINAS, P., El defensor., p.280.

${ }^{13}$ Como por ejemplo, una exclamación de doloral quemarse o un grito de sorpresa al encontrarse con la persona amada.

${ }^{14}$ DE AQUINO., Comentario al Perihermeneias., II., número 3.

${ }^{15}$ Basta para ello hacer uso de un comector de gramática en una computadora modema y observaremos que hay frases que señala como emóneasy que no lo son: simplemente denotan que alguien, con una facultad racional, expresó esa frase y que otro alguien - con la misma facultad intelectual- la entenderá cuando la lea.

${ }^{16}$ SALINAS., Op.cit., p.312.

${ }^{17}$ Cfr. NAVAL, C., Educación, retórica y poética., p.28 y 181.

${ }^{18}$ LÓPEZ QUINTÁS, A., El secuestro del lenguaje., p.4-10.

${ }^{19} \mathrm{Tal}$ es el caso de las conocidas muletillas» que son palabras que se repiten con excesiva frecuencia y que si bien permiten que discurra el pensamiento, buscando el término apropiado o la forma óptima de expresaruna idea, son una señal clara de la pobreza del lenguaje.

${ }^{20}$ Cfr. SALINAS, P., Op.cit., p.311.

${ }^{21}$ Por ejemplo, llamarle schunchestanto a la escoba, como a los lentes o al desamador.

${ }^{22}$ SALINAS, P., Op.cit., p.282.

${ }^{23}$ VILARINI, A.R, Principiospara la integración del currículo., p.13-37. 


\section{BIBLIOGRAFÍA}

ARISTÓTELES., Organon., Pomúa., México., 1993.

BEUCHOT, Maunicio., Posmodernidad, hermeneútica y analogía., UNAMPorrúa., México., 1996., 145 p.

CHOZA, Jacinto., etal., Filosofía del hombre: una antropología dela intimidad., Rialp., Madrid., 1992., 496 p.

DEAQUINO, Tomás., Comentarioal Perihermeneias (en prensa)., Traducción del doctor Jorge Morán., México.

HARGREAVES, Andy., Profesorado, cultura y postmodernidad., Morata., España., 1996., 303 p.

INNERARTTY, Daniel., Dialéctica dela modernidad., Rialp., España., 1990., $136 \mathrm{p}$.

ШANO, Alejandro., La nueva sensibilidad., Espasa., España., 1989., 244 p. LANO, Carlos., El postmodernismo en la empresa., McGraw-Hill., MéxiCo., 1995., $183 \mathrm{p}$.

LÓPEZ QUINTÁS, Alfonso. «El secuestro del lenguaje»en ISTMO., Número 202., 1992.

NAVAL, Concepción., Educación, retórica y poética: tratado dela educación en Aristóteles., EUNSA., Pamplona., 1992., 259 p.

NUBIOLA, Jaime., etal., Filosofía del lenguaje., Herder., Barcelona., 1999., $354 \mathrm{p}$.

SALINAS, Pedro., El defensor., Alianza Editorial., Madrid., 1993., 185 p.

SARTORI, Giovanni., Homo videns., Taurus., México., 1997., 159 p.

VILIARINI, Ángel., Principiospara la integración del currículo., Departamento de Instrucción Pública., Puerto Rico., 1997., 184 p.

YEPES, Ricardo., Entender el mundo dehoy., Rialp., Madrid., 1993., 190 p. YEPES, Ricardo., FundamentosdeAntropología: un ideal dela excelencia humana., EUNSA., Pamplona., 516 p. 